\title{
Preventing disease and promoting health: the need for some new thinking
}

\author{
S. Leonard Syme is Professor Emeritus of Epidemiology and Community Health at the University of California at Berkeley
}

The five papers in this issue of the Journal (Bucksch \& Schlicht 2006; Kloek et al. 2006; Märki et al. 2006; Peres et al. 2006; Weyers \& Kunst 2006) illustrate several important problems that need to be considered in developing programs to prevent disease and promote health. These five papers deal with identifying the determinants of disease and with the challenge of helping people change their behavior to lower disease risk. The urgency of these issues is clear: in the next 10 to 20 years, the number of people over the age of 65 years will almost double in most developed and developing countries of the world. In most of these countries, medical care resources already are strained but they will be challenged as never before when there are twice as many older people to contend with. Our best hope in dealing with this impending crisis to develop more effective disease prevention and health promotion programs so that older people will also be healthier people.

So far, we have not had a good record of success in developing and implementing effective disease prevention programs. Most of the successes we have had in disease prevention have come about through changes in laws and regulations. The paper by Peres et al. (2006) regarding fluoridating community water supplies provides a good example of the power of this approach. However, we have not done as good a job in working with individuals one on one. There are at least three reasons to explain this failure. One reason is that we have not done a good job in identifying disease risk factors. Even in the case of coronary heart disease (CHD), for example, the dozens of obviously important risk factors that we have identified account for less than half of the CHD that occurs. It is difficult to intervene effectively if one is not able to target the important risk factors. The second reason we have had difficulties in disease prevention is that many people do not change behavior to lower disease risk even when they know they should. The evidence is clear from many studies that most people do not respond to appeals even when we do a wonderful job of presenting the case. People do change behavior, of course, but they tend to do it on their own and not in our clinics. The third problem may be the most difficult of all: Even if everyone at risk did change their behavior, new people would continue to enter the at-risk population because we rarely target the fundamental causes of disease at the community and environmental level. As the papers by Weyers \& Kunst (2006) and by Kloek et al. (2006) point out, people living in lower socioeconomic circumstances have the highest rates of risky behavior, the highest rates of physical and psychological morbidity, and the highest rates of mortality. Interventions to change the social class position of these people depends on a clear understanding of the specific components of their lives that are causing the problem: Are these higher rates due to their poverty, low education, inadequate nutrition, poor medical care, hazardous housing, toxic neighborhoods, unsafe jobs, or something else? Which of these is most important? This question cannot be answered, of course, because all of these issues are inextricably intertwined. Short of revolution, then, there usually is little we can do to deal with the most important determinant of health and disease.

As the paper by Weyers \& Kunst (2006) also makes clear, however, the observation of a disease/social class gradient provides an opportunity to think about this problem in a fresh and more creative way. If we could identify risk factors that explain higher disease rates even among people relatively well-off, we might be able to envision more realistic and practical interventions to reduce rates of disease and promote better health.

One of the most interesting features of the gradient is that it applies to so many diseases and involves so many organ systems. This suggests that we might benefit from a more useful system for categorizing diseases. The system we 
Syme SL

Preventing disease and promoting health:

the need for some new thinking

use now is grounded in clinical practice and yields such categories as coronary heart disease, cancer, and arthritis. This system may be useful in the diagnosis and treatment of diseases in individuals but it may not be as useful in the prevention of disease. In efforts to prevent many infectious diseases, epidemiologists classified them into such categories as water-borne, food-borne, air-borne, and vector-borne diseases. This classification system might not have been useful in the treatment of individuals but it certainly identified those aspects of the environment that were associated with the occurrence of disease and it helped to target appropriate interventions. We do not have a similar classification system for many of the non-infectious diseases of concern today. Funding agencies typically would not know how to deal with such categories as poverty disease, nutrition deficiency disease, or inappropriate sexual behavior disease.

If we hope to develop prevention programs that are targeted at fundamental determinants of disease in the social and physical environment, we will need a disease classification system that is appropriate to the task. The papers in this issue of the Journal provide stimulating illustrations of the challenge we face and of some ways to address them. It is likely we will have to pay much more attention to this problem and the articles in this issue provide a wonderful opportunity to begin the dialogue.

S. Leonard Syme

\section{References}

Bucksch J, Schlicht W (2006). Health-enhancing physical activity and the prevention of chronic diseases - An epidemiological review. Soz Praventiv Med 51(5): 281-301.

Kloek GC, van Lenthe FJ, Mertens YMG, Koelen MA, Mackenbach JP (2006). Process Evaluation of a Dutch Community Intervention to Improve Health Related Behaviour in Deprived Neighbourhoods. Soz Praventiv Med 51(5): 259-272.

Märki A, Bauer GF, Nigg CR, Conca-Zeller A, Gehring TM (2006). Transtheoretical Model based exercise counselling for older adults in Switzerland: quantitative results over a 1-year period. Soz Praventiv Med 51(5): 273-280.
Peres MA, Fereira Antunes JL, Glazer Peres $K$ (2006). Is water fluoridation effective in reducing inequalities in dental caries distribution in developing countries? Soz Praventiv Med 51(5): 302-310

Weyers S, Kunst A (2006). Tackling Health Inequalities - two European Programmes will identify effective stratgies from 2004 to 2007 Soz Praventiv Med 51(50): 257-258.

\author{
Address for correspondence \\ S. Leonard Syme, PhD \\ Professor of Epidemiology and Commu- \\ nity Health (Emeritus) \\ School of Public Health \\ 140 Warren Hall \\ University of California \\ Berkeley, CA 94720-7360 \\ USA \\ Phone: (510) 642-3712 \\ Fax: (510) 642-2857 \\ e-mail: slsyme@berkeley.edu
}

